\title{
Optimization of the main tillage in the grey forest rotation of the Predkamye region of the Republic of Tatarstan
}

\author{
Rogat V. Minikayev*, Gulia S. Saifiyeva, and Irina G. Manukova \\ Kazan State Agrarian University, 65, K. Marx Street, Kazan 420015, Republic of Tatarstan, Russia
}

\begin{abstract}
In order to optimize the tillage system by minimizing basic tillage, eight basic tillage options for basic field crops were explored between 2011 and 2015. The highest crop yields were obtained under the fine tillage option (SSC-3) with periodic deep loosening. The yield increase compared to plowing (control) was $0.24-0.33 \mathrm{t} / \mathrm{ha}$.
\end{abstract}

\section{Introduction}

With a high crop yield, optimal crop rotation and sufficient chemicalization, minimum or zero tillage can be used as an element of intensive technology. This is the property of highly professional technologists. Cleaning the fields from weeds, levelling the field surface, various measures for reclamation and liquidation of the plough sole - these are mandatory conditions for the implementation of zero treatment [1].

Intensive search for ways to minimize soil treatment is carried out in Western Europe, England, France and other countries. According to the U.S. forecast service, the minimum tillage in this country has reached $90.5 \%$ of the total arable land area. Today, the zero system is used to cultivate 17.5 sown areas in the USA, 30 in Canada, 45 in Brazil, 50 in Argentina, 60\% in Paraguay. Even more of the planet's surface area is processed using a minimum system [2].

A number of researchers have considered modern soil tillage in the concept of optimizing soil conditions, vegetation cover and increasing soil fertility. For the present period, there are several concepts for basic tillage. Along with supporters of combined systems in crop rotations, where dump, non-dump, surface and zero methods are reasonably combined, there are adherents of systematic small, surface and even zero methods of cultivation [3-8]. In this regard, we considered it important to study the various options for basic tillage in order to optimize the system of tillage by minimizing.

\section{Research goal and objectives}

The aim of the work is to develop minimum methods of autumn tillage in the crop rotation to obtain yields while maintaining soil fertility.

The task of research is:

\footnotetext{
* Corresponding author: ragat@ mail.ru
}

1. to study the influence of different methods of basic cultivation on changes in agrophysical, biological and nutrient properties of soil.

2. Identify the regularities of changes in the contamination of crops and soil.

3 . To determine the influence of the studied methods of soil treatment on the growth and development of cultivated plants, yield and quality of products.

4. Determine economic and energy efficiency of the studied methods of basic soil treatment in crop rotation.

5. To develop and recommend scientifically grounded methods of minimum tillage for production.

\section{Research program and methodology}

In order to study the possibility of minimization of the main tillage on gray forest soils, since 2011 the stationary experience in two bookmarks in the crop rotation has been laid: Sideral steam - winter wheat rape - spring wheat - barley.

Experience is laid on the experimental field of the Department of General Agriculture, Plant Protection and Selection of Kazan State Automobile University on the territory of land use of Laishevsky district of the Republic of Tatarstan. Arrangement of variants in the experiment is one-tier, consecutive. Soil is grey forest medium loamy mechanical composition. The thickness of the arable layer is $24-25 \mathrm{~cm}$. Agrochemical parameters of arable layer have the following values: $\mathrm{pH}$ of salt extract - 5,7; hydrolytic acidity - 5,07 mg/eqv; degree of saturation of bases - $80,39 \%$; humus content $3,59 \%$ (according to Tyurin). Content of P2O5 and K2O (according to Kirsanov) - 156.0 and $78.0 \mathrm{mg}$ per $100 \mathrm{~g}$ of soil, respectively, the content of easily hydrolysable nitrogen - $182.0 \mathrm{mg}$ per $100 \mathrm{~g}$ of soil.

Scheme of experience:

1. $\quad 6-8 \mathrm{~cm}$ of stubble was removed the next day after the previous day by the LDG-3 shredder. In 4 
weeks after the stubble removing the stubble, the plough PN-4-35 was plowed to a depth of $23-25 \mathrm{~cm}$. This variant of "shelling + ploughing" is accepted as a control.

2. Shallow treatment to a depth of $10-12 \mathrm{~cm}$ was carried out by the SIT-3 unit with alternation of periodically after one year of dump-free treatment to a depth of $23-25 \mathrm{~cm}$. This variant is "Fine tillage with nondumping loosening in one year".

3. Shallow tillage to the depth of $10-12 \mathrm{~cm}$ by the SIT-3 unit was carried out with alternation of periodically after two years of non-dump tillage to the depth of $23-25 \mathrm{~cm}$. It is a variant - "Fine processing with non-dumping loosening in two years".

4. Constant shallow treatment was carried out at a depth of $10-12 \mathrm{~cm}$ with the $\mathrm{KSN}-3$ unit (variant "Small, constant").

5. Surface treatment was carried out at a depth of $6-8 \mathrm{~cm}$ by disc harrows BDT-3 with alternation of periodic in one year of non-dumping loosening on depth of 23-25 cm (a variant - "Surface, non-dumping loosening in one year").

6. The surface processing made on depth of 6$8 \mathrm{sm}$ by disk harrows BDT-3 with alternation of periodic in two years of not-dumped loosening on depth of 23-25 sm (a variant - "Surface, not-dumped loosening in two years").

7. Surface processing was made on depth of 6$8 \mathrm{~cm}$ by disk harrows BDT-3 with alternation of periodic in three years of not-dumped loosening on depth of 23$25 \mathrm{~cm}$ (a variant - "Surface, not-dumped loosening in three years").

8. Option - "Zero tillage (direct sowing)".

Repetition is three times, the registration area is 108 $\mathrm{m} 2$.

The following measurements and observations were carried out in the experiments: structural-aggregate composition of soil - by the method of dry screening by the method of N.I. Savinov (A.F. Vadunin, 1986); soil density - by the method of cylinders according to S.I.Dolgovou, GOST 27593-88; soil moisture thermostat-weight method in the modification of CINAO, GOST 26951-86; mobile compounds of phosphorus and potassium - according to the method of Kirsanov, GOST 26204-91 The content of humus in the soil was determined according to Tyurin in the modification of CINAO (GOST 26213-91), $\mathrm{pH}$ of salt extract - according to the method of CINAO (GOST 26483-85), hydrolytic acidity of soil was determined according to Kappen in the modification of CINAO (GOST 26212-84).

In 2011 - 2012, according to the scheme of experience, winter wheat was cultivated according to the generally accepted technologies in the region. Mineral fertilizers were used for pre-sowing cultivation, which was calculated using the balance method for the planned yield level of $3.5 \mathrm{t} / \mathrm{ha}$. Sowing was carried out with the SZ-3.6 seed drill. A variety of winter wheat included in the state register for the Radon region. Seed rate - 6 million germplasm seeds per 1 hectare.

In 2013-2014, we used the variety Ratnik for sowing spring rape. Seeding rate is 2 million germplasm seeds per 1 hectare. Seeds were dressed with Furadon before sowing at the rate of $14 \mathrm{~kg}$ per 1 ton of seeds.

Before sowing spring rape, we cultivated with the KBM-15 unit, sowing with the SZT-3.6 seeder, after sowing, we pressed (KZK-9). Fertilizers were applied for pre-sowing cultivation at the rate of N60 P 45 K60.

According to the scheme of experience, in 2014-2015 spring wheat was cultivated with simultaneous harrowing in the unit KPS - 4.0 was carried out at a depth of 4-5 cm, under which fertilizers were applied, calculated by the balance method for the planned yield of $3.0 \mathrm{t} / \mathrm{ha}$. Sowing was carried out with the sowing machine SP-3,6. Sort of spring wheat Zlata, sowing rate of 5 million germinated seeds per 1 ha.

In 2015, barley was cultivated. Barley variety Raushan. Seed rate - 5 million germplasm seeds per 1 hectare. Before sowing, the seeds were dressed with Timer fungicide $(0.5 \mathrm{l} / \mathrm{t})$. Calculation of mineral fertilizers application was made by the balance method on the planned yield of barley grain of $3.0 \mathrm{t} / \mathrm{ha}$.

The crops were treated against weeds in the phase of tillering with a tank mixture of herbicides Secator $(0.2$ 1/ha) + Puma Super 7.5 (0.9 1/ha). Spraying against aphids with Tippor (0.2 1/ha).

The growing season of 2013 was characterized by extremely unfavorable meteorological conditions in relation to the average annual data, which affected the yield of spring rape.

The growing season of 2012, 2014, 2015 was relatively favorable for the growth and development of crops compared to the average annual data. The nature and amount of precipitation, as well as the temperature regime, which are usually limiting factors, were optimally developed during the growing season.

\section{Results}

Soil density is an agronomically important indicator of soil addition.

In our experiments, the dependence of soil density on the methods of its basic cultivation has been established (Table 1).

The density of soil addition in all variants was within the optimal values for growth and development of the crops under study $-1.0-1.3 \mathrm{~g} / \mathrm{cm}^{3}$.

As the soil settled naturally, the impact of precipitation and other factors the soil on winter wheat sowing gradually compacted and by the spring vegetation resumption the density of addition in the layer of $0-20 \mathrm{~cm}$, depending on the methods of loosening, varied from $1.24-1.32 \mathrm{~g} / \mathrm{cm}^{3}$. On the variant of direct sowing the soil compacted above optimal parameters. On the variant of direct sowing the soil compacted above the optimum indicators (Table 1).

According to the change in soil density, its hardness also changed. So, hardness of soil before sowing winter wheat in the top layer of soil $(0-10 \mathrm{~cm})$ in the first variant and variants of fine and surface loosening was $9.8-16.2 \mathrm{~kg} / \mathrm{cm} 2$, and in zero tillage $-17.1 \mathrm{~kg} / \mathrm{cm} 2$. Indicators in the layer of $10-20 \mathrm{~cm}$ differed more 
sharply, which was $18.3 \mathrm{~kg} / \mathrm{cm} 2$ in ploughing and 31.7 $\mathrm{kg} / \mathrm{cm}^{2}$ for zero machining.

Table 1. Soil addition density in the $0-20 \mathrm{~cm}^{3}$ layer in spring with different tillage systems according to the average data of 2011-2015

\begin{tabular}{|c|c|c|c|c|c|c|c|c|}
\hline $\begin{array}{c}\text { Grain } \\
\text { cultures, } \\
\text { Fields }\end{array}$ & 1 & 2 & 3 & 4 & 5 & 6 & 7 & 8 \\
\cline { 2 - 9 } $\begin{array}{c}\text { Green_- } \\
\text { manured_fa } \\
\text { llow }\end{array}$ & $\begin{array}{c}1.1 \\
3\end{array}$ & $\begin{array}{c}1.1 \\
3\end{array}$ & $\begin{array}{c}1.1 \\
3\end{array}$ & $\begin{array}{c}1.1 \\
5\end{array}$ & $\begin{array}{c}1.1 \\
2\end{array}$ & $\begin{array}{c}1.1 \\
4\end{array}$ & $\begin{array}{c}1.1 \\
6\end{array}$ & $\begin{array}{c}1.2 \\
2\end{array}$ \\
\hline Winter & 1.2 & 1.2 & 1.3 & 1.3 & 1.3 & 1.3 & 1.3 & 1.3 \\
wheat & 4 & 8 & 0 & 1 & 0 & 1 & 2 & 5 \\
\hline Rapeseed & 1.1 & 1.2 & 1.2 & 1.2 & 1.2 & 1.2 & 1.2 & 1.2 \\
& 8 & 2 & 4 & 1 & 1 & 0 & 4 & 6 \\
\hline Spring & 1.1 & 1.1 & 1.1 & 1.2 & 1.1 & 1.1 & 1.2 & 1.2 \\
wheat & 8 & 8 & 9 & 0 & 9 & 9 & 1 & 3 \\
\hline Barley & 1.2 & 1.2 & 1.2 & 1.2 & 1.2 & 1.2 & 1.2 & 1.2 \\
& 0 & 0 & 2 & 2 & 1 & 2 & 3 & 7 \\
\hline Average & 1.1 & 1.2 & 1.2 & 1.2 & 1.2 & 1.2 & 1.2 & 1.2 \\
score & 9 & 0 & 2 & 2 & 1 & 1 & 3 & 7 \\
\hline
\end{tabular}

The highest soil hardness in the crop rotation was in the variant with constant surface (BDT-3) and zero tillage - $16.2-17.1 \mathrm{~kg} / \mathrm{cm} 2$ in the layer $0-10$ and $30.5-$ $31.7 \mathrm{~kg} / \mathrm{cm} 2$ in the layer $10-20 \mathrm{~cm}$.

A similar pattern was observed in determining the soil density in the crops of other crops under study.

During the vegetation period in the soil of all variants of experience, its hardness increased and became almost the same everywhere for harvesting. Therefore, the hardness and density of grey forest soil formation correlates with each other. The index of direct correlation dependence $r=0.73$.

The structure of the arable layer of soil also changes depending on the methods of its cultivation. So, before sowing winter wheat, the total load factor of the soil in the arable layer of ploughing was $50.3 \%$, in the constant fine and surface layer, respectively, $44.0-45.6 \%$, and at zero tillage $-41.8 \%$.

Minimization of soil treatment contributed to reduction of general load factor in the arable layer of soil and other crops under study.

Reduction of the total load factor of the soil is mainly due to the reduction of its non-capillary load factor.

As a whole, it is necessary to note that at ploughing more favorable parity between capillary and noncapillary load factor is created.

Before the harvest, the overall load factor for all the studied crops decreased due to an increase in capillary load factor and a decrease in non-capillary load factor. However, the obtained values were within the optimal parameters for grey forest soils (47-56\%).

In experiments it is established that methods of soil treatment have a great influence on its water regime that depends on the ability of soil to absorb and retain moisture of falling precipitation.

On variants of soil processing the greatest stocks of a productive moisture before sowing in a meter layer of soil under a winter wheat and other researched cultures have accumulated on small loosening (KSN-3) - 168.0$185.0 \mathrm{~mm}$; on superficial processing (BDT-3) -161.7 -
$176.8 \mathrm{~mm}$; on ploughing $162.7-173.6 \mathrm{~mm}$ and on zero processing - 160.3-170.0 mm. From two ways of processing by aggregates $\mathrm{KSN}-3$ and BDT-3 advantage has small processing of KSN-3 in 1 year as in all phases of development of studied cultures indicators of humidity on this variant appeared above, than on ploughing, superficial and zero processing.

Under the influence of different methods of soil treatment the infestation of crops under study has changed differently (Table 2).

Table 2. Changes in clogging of crops under the influence of basic cultivation methods (Tube exit phase, $\mathrm{pcs} / \mathrm{m}^{2}$ )

\begin{tabular}{|l|c|c|c|c|c|c|c|c|}
\hline $\begin{array}{l}\text { Grain } \\
\text { cultures, } \\
\text { Fields }\end{array}$ & \multicolumn{7}{|c|}{ Processing methods } \\
\cline { 2 - 10 } & 1 & 2 & 3 & 4 & 5 & 6 & 7 & 8 \\
\hline $\begin{array}{l}\text { Winter } \\
\text { wheat }\end{array}$ & 31 & 30 & 33 & 37 & 32 & 35 & 40 & 47 \\
\hline $\begin{array}{l}\text { Spring } \\
\text { rape }\end{array}$ & 5 & 3 & 4 & 8 & 6 & 8 & 9 & 14 \\
\hline $\begin{array}{l}\text { Spring } \\
\text { wheat }\end{array}$ & 4 & 7 & 8 & 6 & 8 & 7 & 6 & 12 \\
\hline Barley & 8 & 9 & 11 & 10 & 11 & 14 & 15 & 18 \\
\hline
\end{tabular}

In the phase of entering the tube of cereals, rapeseed stem plowing was replaced by constant fine plowing (SCC-3), surface treatment with a unit (BDT-3), as well as zero treatment contributed to an increase in contamination (Table 2). Fine treatment in combination with periodic non-dumping loosening after 1.2 years contributed to keeping the clogged crops of the studied crops practically at the level of ploughing. Surface treatment in combination with periodic non-dumping loosening in 2 years increased the number of weeds, including doubled the contamination of perennial weeds. The highest degree of contamination was noted at zero treatment. Compared to ploughing, the number of weeds in all crops increased from 8 to $16 \mathrm{pcs} / \mathrm{m} 2$ and the number of perennial weeds tripled.

Thus, the periodically non-deposited loosening after 1 and 2 years on the background of shallow and surface treatment, although it reduced the number of weeds, but they were still more than during ploughing.

Different methods of soil treatment had almost no effect on the contamination of the studied crops. The structure of weeds from underage weeds was dominated by the smoke of medicinal plants - Fumaria officinalis (L.), Chenopodium album (L.), Poligonum convolvulus (L.), Amaranthus retroflexus, Galeopsis spesiosa, Galium aparine $(L$.$) , Viola arvensis (L$. $)$ and others.

Thus, at replacement of ploughing on superficial and small cultivating and at their combination with deep безотвальных loosening at pre-sowing preparation of soil under winter wheat small cultivating by the unit $\mathrm{KCH}-3$ on a background of deep loosening is rather more effective in struggle against contamination.

Seed stocks in soil confirm the difference in contamination. Determination of weed seeds in the arable layer showed that for the fifth year after the initial detection of the content of weed seeds, their differentiation in the arable layer is noticeable. On 
ploughing weed seeds are distributed more evenly in the arable layer, and in variants with shallow and superficial and their combinations with deep non-dump loosening, and also at zero processing weed seeds differentiation on soil layers occurs, i.e. the most part of them accumulates in the top layer of soil.

The main disease of grain crops in industrial crops is root rot. Infection of plants with root rottenness before harvest was $40.1 \%$ of winter wheat, $23.1 \%$ of spring wheat and $21.2 \%$ of barley. On fine processing by KSN3 unit accordingly: $48.2 ; 26.2$ and $23.4 \%$, and 49.7; 27.1 and $27.3 \%$ on surface treatment. The greatest affection of root rot sowings is noted on the variant with zero treatment - $56.2 \%$ in winter wheat, $32.5 \%$ in spring wheat and barley. Accumulated and not mineralized stubble remains are sources of infection.

A similar pattern of soil contamination with phytopathological fungi was observed in rapeseed crops.

At use of various methods of the basic processing of soil, despite arid conditions of a number of years, it is received rather high productivity of grain crops for the Predkamsk zone of the Middle Volga region: winter wheat, spring wheat and barley (tab. 3).

Table 3. Crop yields depending on the methods of basic tillage, t/ha (2012-2015)

\begin{tabular}{|l|c|c|c|c|c|c|c|c|}
\hline Grain & \multicolumn{10}{|c|}{ Processing method } \\
\cline { 2 - 10 } $\begin{array}{l}\text { cultures, } \\
\text { metrics }\end{array}$ & 1 & 2 & 3 & 4 & 5 & 6 & 7 & 8 \\
\hline Winter & 3. & 3.4 & 3.2 & 3.0 & 3.3 & 3.1 & 2.8 & 2.7 \\
wheat & 15 & 8 & 6 & 5 & 1 & 9 & 1 & 1 \\
\hline Spring & 1. & 0.9 & 0.9 & 0.9 & 0.8 & 0.8 & 0.8 & 0.8 \\
rape & 13 & 0 & 1 & 2 & 8 & 7 & 5 & 1 \\
\hline Spring & 3. & 3.2 & 3.2 & 2.7 & 2.8 & 2.9 & 2.7 & 2.5 \\
wheat & 03 & 8 & 1 & 8 & 7 & 6 & 4 & 3 \\
\hline Barley & 3. & 3.5 & 3.2 & 3.0 & 3.3 & 3.1 & 2.9 & 2.8 \\
& 27 & 1 & 3 & 2 & 4 & 6 & 2 & 5 \\
\hline $\begin{array}{l}\text { Cereal } \\
\text { yield }\end{array}$ & 3. & 3.4 & 3.2 & 2.9 & 3.1 & 3.1 & 2.8 & 2.6 \\
\hline $\begin{array}{l}\text { Product } \\
\text { ivity of } \\
\text { the crop }\end{array}$ & 13 & 13 & 3 & 5 & 7 & 0 & 2 & 9 \\
rotation, & & 62 & 96 & 92 & 64 & 36 & 35 & 85 \\
unit/ha & & & & & & & & \\
\hline
\end{tabular}

Relatively high yield of winter wheat was formed on fine processing on background with periodic deep loosening - 3.19-3.48 t/ha, on ploughing - 3.15 t/ha. Constant fine processing reduced yield by $-0.1 \mathrm{t} / \mathrm{ha}$.

Surface treatments with periodic deep loosening provided yield much lower than with fine treatments. Reliable decrease in yields was observed in surface treatment, carried out four years in a row, the difference from the control was $-0.34 \mathrm{t} / \mathrm{ha}$. Zero treatment (direct sowing) provided the obtained 2.71 tons, which is 0.44 tons lower than the control and $0.48-0.77$ tons per hectare than the fine treatment on the background with periodic loosening.

Low yield of spring rape can be explained to the greatest extent due to dry conditions of vegetation in 2013. These yield structures confirm the superiority of autumn ploughing when cultivating rape for seeds (the number of plants before harvesting is $138 \mathrm{pcs}$. / ha, pods per plant is 41.4 pcs.

$109-110$ plants per $\mathrm{m}^{2}$ and the number of pods $-29.2-$ 34.3 pcs.) Comparatively low yield of all cereals in the variant with direct sowing is explained by a sharp increase in contamination by perennial weeds.

On average, over three years, grain yield and productivity of crop rotation depending on the studied methods of soil treatment changed significantly and amounted to $2.85-3.51 \mathrm{t} / \mathrm{ha}$.

Over the years of research the lowest production costs in the variant of direct sowing of grain crops, which is an average of 12297 rubles/ha. On this variant of experience because of lower yield in comparison with other variants of experience low economic effect is received. In the variant of combination of fine processing with loosening in a year the economic effect of cultivation of grain crops was higher than the control. At the same time, the net income increased by 2424 rubles/ha and the profitability level increased by $26 \%$ compared to the control.

Determination of economic efficiency of application of various methods of the basic processing of soil under spring rape at cultivation on seeds has allowed to establish that the best results have been reached on variants with zero and small processing. The conditionally net income increased by $180-440$ rubles/ha $(11.2-13.0 \%)$ and the profitability level by $8.1-9.2 \%$, in relation to the control.

\section{Conclusion}

During the main preparation of grey forest soil in the Pre-Cameroon of the Republic of Tatarstan, it is expedient to replace ploughing for sowing the main field crops with small treatment of CSP-3 or surface treatment of BDT-3.

\section{References}

1. P. V. Minikaev, A. R. Valiev, V. F. Mareev, I. G. Manukova, G. S. Saifieva, Proc. of Kuban State Agrarian University 6(45), 121-124 (2013)

2. O. I. Goryanin, Izvestiya of Orenburg State Automobile University 3(35), 23-26 (2012)

3. V. I. Kiryushin, Farming 5, 12-14 (2006)

4. V. I. Kiryushin, Farming 6, 6-10 (2015)

5. M.F. Amirov, Adaptive technologies of cultivation of field crops 124 (Brig, Kazan, 2018)

6. P. V. Minikaev, G. S. Sayfiyeva, I. G. Manukova, Grain Farm of Russia 2(50), 47-51 (2017)

7. V. M. Novikov, Plant Protection and Quarantine 1, 24-25 (2008)

8. A.S. Salikhov, Resource-saving methods in agriculture in the middle Volga region 200 (Kazan State University, Kazan, 2008) 